\title{
The distribution of Lignin and Xylan in the Inner and Surface Layers of the Fiber from Eucalyptus Kraft Pulp and its Effects on Oxygen Delignification
}

\author{
Giovani Boaventura Bacarin ${ }^{a}$, Flávio Camargo Cabrera ${ }^{a}$, Marcelo Rodrigues da Silva ${ }^{b}$, Aldo Eloizo Job ${ }^{a *}$ \\ ${ }^{a}$ Faculdade de Ciências e Tecnologia - FCT, Universidade Estadual Paulista Júlio de Mesquita Filho - \\ UNESP, Departamento de Física, Quimica e Biologia, 19060-900, Presidente Prudente, SP, Brasil. \\ ${ }^{b}$ Klabin S/A, 84350-000, Ortigueira, PR, Brasil.
}

Received: September 18, 2016; Revised: April 19, 2017; Accepted: May 21, 2017

\begin{abstract}
The chemical structure and composition of lignin and hemicellulose, as well as the distribution between inner and outer layers of fiber, can adversely affect bleaching operations or fiber-fiber bond on pulp and, consequently the papermaking process. Herein, we have implemented the fractionation and mechanical peeling techniques in order to identify the fines composition from eucalyptus cellulose as well as to verify the effect over xylan and lignin contents and the impact on oxygen delignification. Lignin and xylans in the material removed from the fiber surface (fines) were measured around to $7.6 \%$ and $12 \%$ of the composition, respectively. The lignin value is three times higher than the percentage measured to original fiber composition (without treatment). The residual xylans content on the pulp, after treatment of fines removal and peeling, was slightly reduced, around 3\% for both treatments as well as fractionation and peeling methods decrease the oxygen delignification efficiency.
\end{abstract}

Keywords: Xylans, Lignin, Fractionation, Mechanical peeling, Fiber surface, Oxygen delignification

\section{Introduction}

Cellulose is the most abundant organic compound in the world composed by a straight chain and hydrophilic polysaccharide of repeating $\beta$-D-glucopyranose monomers units which are linked together by (1-4) glycosidic bonds ${ }^{1,2}$. Currently, studies are focused on softwood, mainly from Pinnus $^{2,3,4}$. Due to the climate adaptation and the costeffectiveness, the use of hardwood, mainly extracted from eucalyptus, has emerged as a distinct field in tropical countries as Australia, Brazil, etc. Cellulose has been applied as the main raw material to produce various types of paper such as printing \& writing, tissue, specialties, packing paper and others. The fibers present several interesting properties particularly low density, bio- renewable and wide availability in various morphologies.

The achievement of a higher yield process and a suitable quality pulp and paper are closely related to the remain of a small residual of lignin after wood cooking. This residual must be removed in the bleaching stages. Moreover, hemicelluloses require special attention since as higher it amount result in an easier paper production. Hemicellulose has been directed to the structure of O-acetyl-4-O-methylglucuronoxylan or simply xylan, which are the main hemicellulose of eucalyptus ${ }^{5,6,7}$.

In the 1960s, Kallmes ${ }^{8}$ introduced a mechanical peeling method in order to separate outer layers from fiber wall. The peeling methodology aims to better understand the distribution of the main chemical components across the fiber wall.

*e-mail: job@fct.unesp.br
Other peeling techniques such as chemical (heterogeneous acetylation $)^{9}$ and enzymatic ${ }^{10,11}$ have been applied to isolate the outermost surface layers.

Here, we report the use of fractionation and mechanical peeling in order to verify the xylan and lignin contents and its distributions in the inner and outer layers of the hardwood fibers, as well as the impact on oxygen delignification. As the majority of studies are related to the softwood, the knowledge regarding distribution of xylan and lignin are essential for understanding the eucalyptus fiber behavior leading to the improvement on methodology process from cellulose kraft industry.

\section{Materials and Methods}

The pulp used in this study was an unbleached eucalyptus hardwood kraft pulp, collected after third press (washing), after cooking, in a mill with bleaching sequence $\mathrm{Oa}(\mathrm{Ze}) \mathrm{DP}$. The pulp was diluted at $3 \%$ with demineralized water and after 10 minutes it was dewatered on a 200 mesh screen. The washing water was recovered three times in order to recovery fines.

The fractionation and mechanical peeling was performed using Kallmes technique, according to the proceeding modified by Heijnesson et al. ${ }^{3}$ After washing, the pulp was diluted at $1 \%$ with demineralized water and dewatered on a 200 mesh screen. This procedure was repeated three times, recovering washing water in order to recovery fines. The filtrate was 
collected and centrifuged to separate fibrous material, which was dried at $70^{\circ} \mathrm{C}$. Mechanical peeling was carried out after primary fractionation, by diluting the pulp at $4.5 \%$ with demineralized water and submitted to the mechanical treatment in a disintegrator at 200.000 revolutions. After this treatment the pulp was fractioned again. The fine fraction was collected for further analysis.

The oxygen pre-delignification was carried out using the treated pulp which was delignified with oxygen in a reactor/mixer Mark V, made by Quantum Technologies, with samples of $280 \mathrm{~g}$ a.d of pulp. Treatment conditions were defined as $10 \%$ dryness, at $100^{\circ} \mathrm{C}$, during 50 minutes, with both $18 \mathrm{~kg} /$ ton of charge of Sodium Hidroxide and Oxygen at 4 bar of pressure.

The pulp was deposited in the reactor with suitable dryness and heated up to $100^{\circ} \mathrm{C}$. When the temperature was reached up to $100^{\circ} \mathrm{C}$ and under constant agitation, it were injected pre-establish loads of $\mathrm{NaOH}$ and $\mathrm{O}_{2}$ into the system, increasing the reaction pressure up to 4 bar. After completed time reaction samples of residual liquor were taken for $\mathrm{pH}$ analyze. Then, pulp was exhaustively washed with distilled water, centrifuged at domestic centrifugal and disaggregated manually. Analytical determinations performed during the study and its respective technical standards used are described in the Table 1.

Table 1. Analytical procedures and its respective technical standards.

\begin{tabular}{cc}
\hline Analysis & Standards \\
\hline Kappa number & Scan C01:00 \\
Viscosity & Tappi T230 om-08 \\
Klason Lignin & Tappi T222 om-98 \\
Carbohydrates & Tappi T249 \\
Acids Groups & Scan CM 65:02 \\
Charge of fíber & Acording to the Waberg (1989) \\
Chemical Oxygen & Std. Methods for Water and \\
Demand & Wastewater $-5220 \mathrm{D}$ \\
Britt Jar Fines & Tappi T261 cm-94 \\
Hexenuronics Acids & Hidrolysis acid + UV method \\
\hline
\end{tabular}

\section{Results and Discussion}

In order to evaluate the composition of the fines fractionation and peeling methods were carried out. Table 2 shows results of kappa number, viscosity and hexenuronic acids for unbleached pulp and its standard deviations.

Fractionation reduced 0.7 units of the kappa number for unbleached pulp, i.e. the removed fines during fractionation operation are rich in lignin and hexenuronic acids. Probably, only lignin-rich since the hexenuronic acids show no significant changes as consequence of fractionation treatment.

The lignin found in the fiber surface can be originated from a precipitation phenomenal. Sundin ${ }^{12}$ verified that the lignin precipites when the $\mathrm{pH}$ is reduced with a consequent
Table 2. Kappa number, viscosity and hexenuronic acids content in the treated and untreated unbleached pulps.

\begin{tabular}{lccc}
\hline Characteristies & $\begin{array}{c}\text { Original } \\
\text { Pulp }\end{array}$ & $\begin{array}{c}\text { Fractionated } \\
\text { Pulp }\end{array}$ & Peeled Pulp \\
\hline Kappa number & $16.65 \pm 0,47$ & $15,98 \pm 0,40$ & $14,88 \pm 0,79$ \\
Viscosity, $\mathrm{cm}^{3} / \mathrm{g}$ & $1249 \pm 38,31$ & $1222 \pm 21,28$ & $1157 \pm 34,29$ \\
$\begin{array}{l}\text { Hexenuronics } \\
\text { acids, mmol/g }\end{array}$ & $78,06 \pm 0,76$ & $77,38 \pm 0,65$ & $75,27 \pm 0,55$ \\
\hline
\end{tabular}

protonation of acid groups of the lignin. Furthermore, the adsorption of lignin are related to the bleaching process. The tendency of closing bleaching circuits results in an accumulation of dissolved organic materials, from the formation of colloidal complexes and its posterior precipitation on the fiber, in conditions of low $\mathrm{pH}^{13}$.

The removal of surface material by peeling operation led to the kappa number reduction in approximately $11 \%$ (around to 1.1 units) also attributed to the significant amount of lignin in the fines composition. This is plausible if we consider that, the fiber surface is the nearest part of what was the middle lamella, a region extremely rich in lignin $^{3}$. Nevertheless, for levels of kappa number in question would not be possible to find traces of middle lamella material. Another possibility is that there in the end of the cooking or during industrial washing of unbleached pulp the occurrence of the lignin precipitation phenomenal ${ }^{9}$.

The viscosity presented the same reduction trend for treated pulps. That is, both fines removal as fiber surface bring deterioration of carbohydrates chain. Rely on the treatments are purely mechanical i.e. there is no chemical action, the viscosity reduction must be related to the removal of polymeric material with high molecular weight, or consequently, with high polymerization degree, that is, cellulose. As the viscosity is strongly related to the average degree of polymerization of the fibers, its reduction would be related to the removal of these polymers with higher polymerization degree. In the table 3 we have the results of oxygen delignification (kraft-O) and its standard deviations, performed on unbleached pulps.

Table 3. Kappa number, delignification efficiency, viscosity and hexenuronics acids content after kraft-O.

\begin{tabular}{|c|c|c|c|}
\hline Characteristics & Original Pulp & $\begin{array}{l}\text { Fractionated } \\
\text { Pulp }\end{array}$ & Peeled Pulp \\
\hline Kappa number & & $12,05 \pm 0,53$ & \\
\hline $\begin{array}{l}\text { Delignification } \\
\text { Efficiency, \% }\end{array}$ & (1) & $24,59 \pm 1,52$ & $19,02 \pm 1,41$ \\
\hline $\begin{array}{l}\text { Viscosity, } \\
\mathrm{cm}^{3} / \mathrm{g}\end{array}$ & $1084 \pm 24,18$ & $1087 \pm 14,09$ & $1083 \pm 19,34$ \\
\hline $\begin{array}{l}\text { Hexenuronics } \\
\text { acids. } \mathrm{mmol} / \mathrm{g}\end{array}$ & $68.45 \pm 1,33$ & $68,42 \pm 1,97$ & $68,97 \pm 0,60$ \\
\hline
\end{tabular}

There is a slight reduction of the hexenuronic acids after kraft-O for fractionation and peeling processes. The HexA reduction was $12 \%$ in the original and fractionated pulps, 
but for peeled pulp the removal of HexA was only $8 \%$. HexA removal during oxygen delignification was limited in a value around $68 \mathrm{mmol} / \mathrm{kg}$. It is understood that this limit is that reached through alkaline leaching of the pulp material, that is, there is a limit for xylan removal, which carriers HexA units.

Both the fines removal (fractionation) and the fibers surface (peeling) affected negatively the oxygen delignification, trough reduction of the delignification efficiency. Considering the low effect of the hexenuronic acids in reactions of oxygen delignification, the efficiency loss would be linked to the lower lignin removal. However, data in the Figure 1 shows that there was an increase in lignin removal rate. For the original pulp, lignin content was reduced in $22 \%$, while for the fractioned and peeled pulps the lignin removal rate was 25 and $31 \%$, respectively. That is, it is verified a discrepancy between values of kappa number, hexenuronic acids and lignin content in the pulps, before and after oxygen delignification.

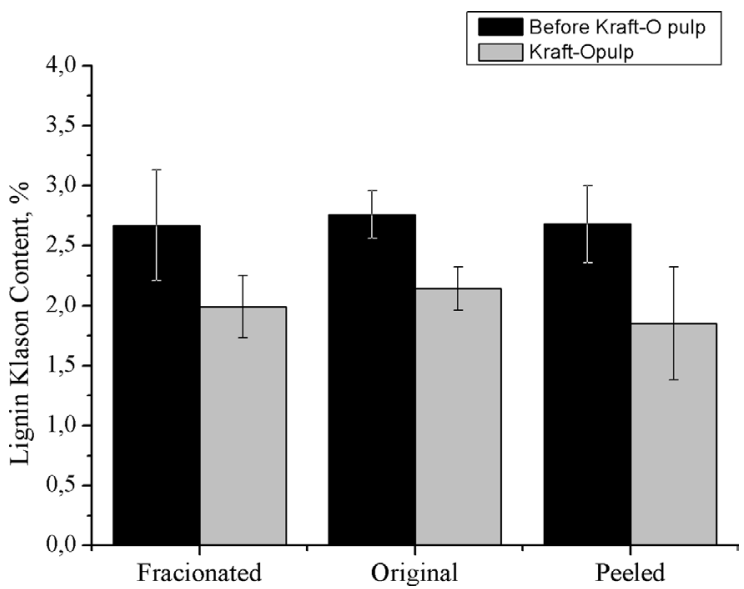

Figure 1. Lignin Klason content in the original and treated pulps.

There are chemical linkages between lignin, cellulose and hemicellulose and the structure that has covalent bonds between lignin and carbohydrate is called lignin-carbohydrate complex $(\mathrm{LCC})^{14}$. In accordance with Gellerstedt \& $\mathrm{Li}^{15}$ these structures are formed during kraft cooking and during oxygen delignification. Therefore, a possible explanation for reducing of the delignification efficiency obtained in this study, even with the reduction of lignin content, would be a higher contribution of the LCC's.

According to the Costa $\&$ Colodette ${ }^{16}$, kappa number measures the total amount of material in the pulp that is oxidizable with $\mathrm{KMnO}_{4}$. However, the method does not distinguish between oxidizable material in the residual lignin and in other structures, such as HexA's, extractives and carbonyl groups in the pulp.

The two main fractions of the kappa number in kraft pulp are residual lignin and HexA. The HexA's interfere with pulp determination of residual lignin by kappa number technique.
Only a small fraction of the kappa number is due to unsatured structure derived from carbohydrates and extractives in the pulp. It has been demonstrated that the oxidation of these structures consumes different amounts of $\mathrm{KMnO}_{4}$.

The kappa number of kraft-O eucalyptus pulp has the main contribution coming from mainly the lignin content and hexenuronic acids. According to that, an important factor that contributes for the kappa number is the LCC fraction (Lignin Carbohydrates Complexes).

Whereas examination of lignin Klason analysis is one of more precise technique for determining the residual material to be removed in the subsequent bleaching, it is concluded that bleachability of the peeled pulp should be higher compared to other pulps, as their lower lignin content for a same kappa number and the same hexenuronics acids level.

The Figure 2 presents xylan content found in the original and treated pulps.

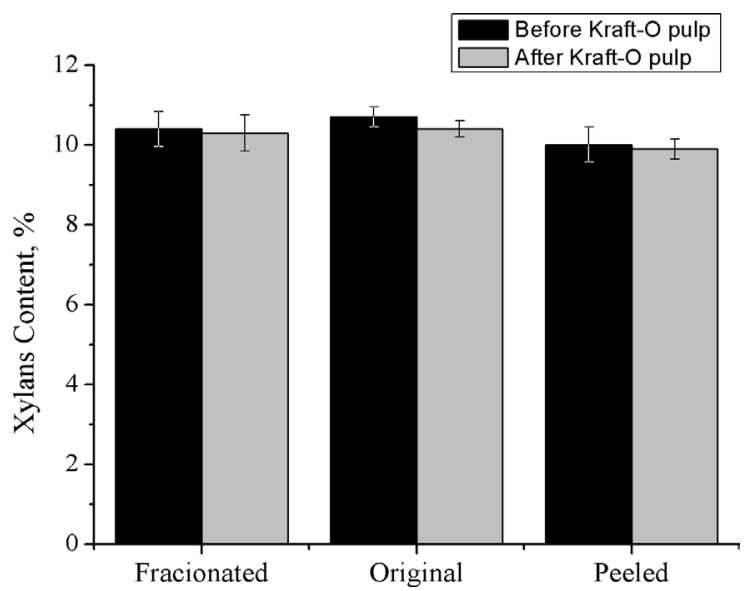

Figure 2. Xylans content in the original, treated and delignified with oxygen pulps.

In the original pulp, before treating, with kappa number of 16.65 , xylans content found was $10.7 \%$, what is coherent with results found by Dang ${ }^{2}$, where is reported that a kraft pulp of eucalyptus urograndis with kappa number of 18.6 showed $13.9 \%$ of xylan content.

Xylans content after treatment of fines removal and peeling were slightly reduced, around $3 \%$ for both treatments. Furthermore, it seems that there is a limit to the reduction of this fraction of carbohydrates by oxygen delignification, since that fractionation and peeling treatments had values practically equal between unbleached and pre- delignified pulps, what is in accordance with Gellerstedt $\& \mathrm{Li}^{15}$.

In the Figure 3 we can see xylan content found in the surface material was $12 \%$. If we consider the lignin content found, we can conclude that the fraction of cellulose is that more, because in the end of cooking the middle lamella, which is lignin-rich, it has been completely removed.

The lignin content in the material removed from the surface (Figure 3 ) has presented a value tree times higher 


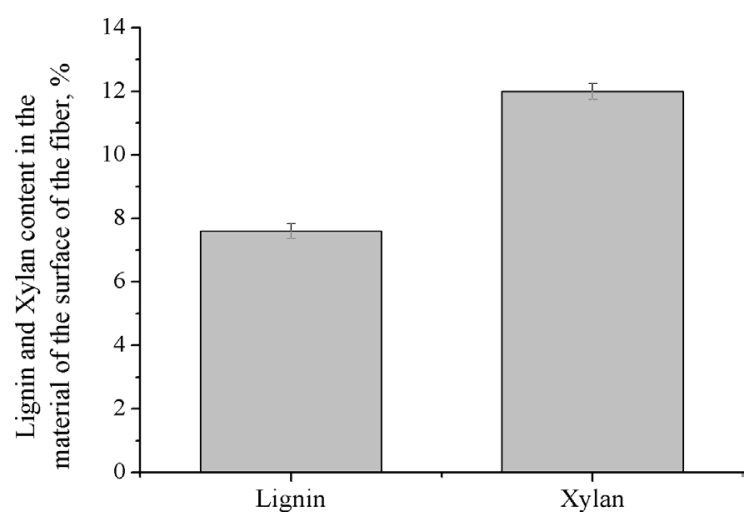

Figure 3. Lignin and xylan in the secondary fines (peeling) of the unbleached pulp.

than the fiber $(7.6 \%)$ what is coherent with the results presents by Heijnesson et $\mathrm{al}^{3}$.

During kraft cooking of the wood, polysaccharides, mainly hemicelluloses, are partly degraded by cooking liquor, within the cell wall, as well as in the phase liquor after its dissolution. Some of these solubilized molecules are redeposited on surface of the fiber, even during the cooking ${ }^{17}$. The xylan adsorption on fibers generates a surface rich in xylan, which in turn, can be significant affect properties of fiber-fiber bond of the pulp ${ }^{18}$.

Side groups of the xylan also are changed during the cooking. The acid group 4-O-methylglucuronic of the xylan chains is converted, almost completely, in acid 4-desoxihex4 -enuronic, or so called hexenuronic acids ${ }^{19}$. These protect xylans against terminal depolymerization reaction, and hence, its presence in the pulp preserves the yield. When wood pulp fiber is suspended in water, this fiber carries a charge due to the presence of acidic groups in the cellulose, hemicellulose and lignin ${ }^{2}$.

Figure 4 indicates that the fractionation operation removed around $20 \%$ of fines, coming out of $11.4 \%$ and going to $8.9 \%$. The treatment of surface material removal of the fibers affected marginally fines content of the pulp. Oxygen delignification increased the fines content in the original and fractionated pulps, remaining practically similar between peeled pulps. Consequently, that fines generated during pre-delignification are attributed to fiber surface, as when this surface is removed in a treatment, delignification with oxygen no longer has the same effect.

Correlations between physical-mechanical strength properties with surface properties of the fibers have been studied. The number of ionizable groups is known to improve indirectly, the strength properties of the paper. The greater amount of ionizable groups in the fibers, more they will swell, increasing its flexibility and conformability ${ }^{20}$.

From all acids groups found in an unbleached pulp, the carboxylic acids groups are those more ionizable, due to its pKa. The carboxylic acids groups can be divided between those which are in the surface and those which are within

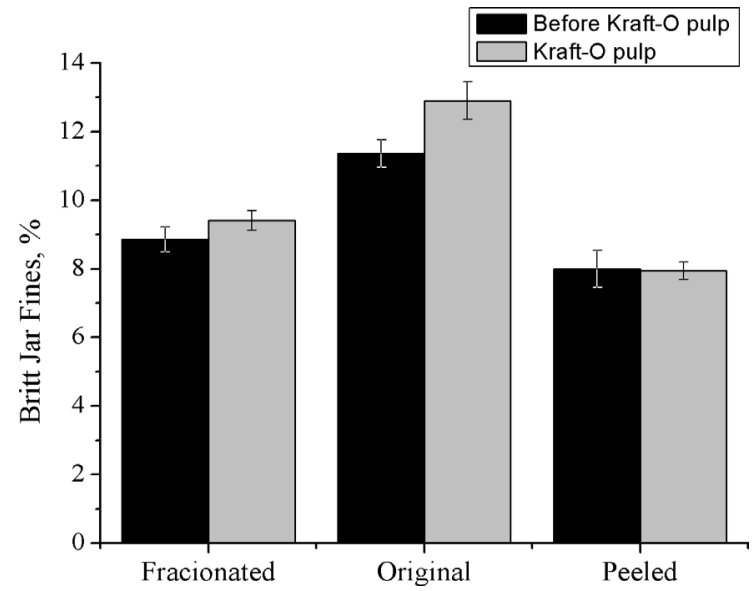

Figure 4. Britt Jar fines content in the original, treated and delignified with oxygen pulps.

cell wall ${ }^{2}$. Bhardwaj et $\mathrm{al}^{21}$, reported that the total content of carboxylic acids groups of a fiber is positively proportional to the kappa number of the pulp. Different cooking technologies also generate different content of carboxylic acids groups ${ }^{22}$.

In the Figure 5, it is shown that fines removal reduced the amount of ionizable groups.

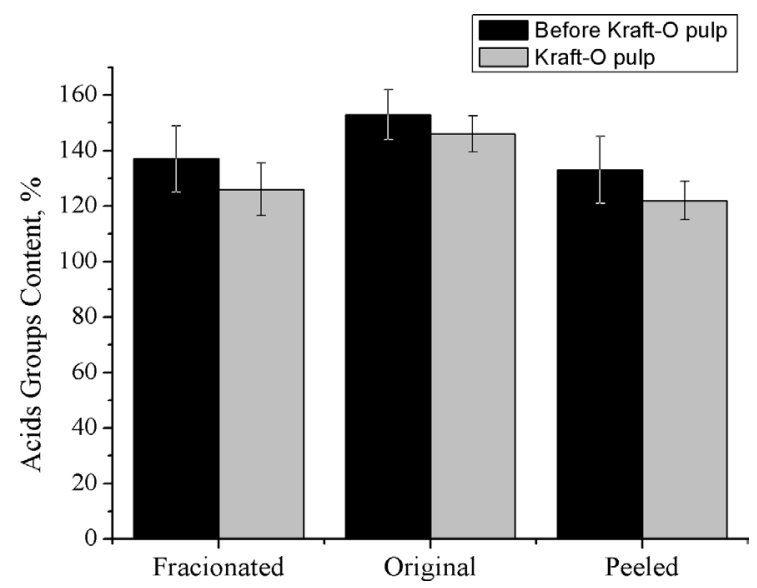

Figure 5. Acids groups in the original, treated and oxygen delignified pulps.

Kangas \& Kleen ${ }^{23}$ noted that the fines are composed mostly by lignin, extractives and xylans. These groups are known to contain appreciable amount of ionizable groups, what explain the decrease in the results of the fractionated pulp. This is evidenced by the presence of high lignin content in the fines $(\sim 7.6 \%)$.

The oxygen delignification reduces acids groups of the pulps, because there is carbohydrates and lignin removal, which have ionizable groups. The fines are in charge of a significant part of the acids groups in the pulp, because show a high lignin content. 


\section{Conclusions}

Eucalyptus hardwood pulps studied showed that fines removal through fractionation and peeling treatments leads to the carbohydrates chain deterioration. Not having any chemical action in these treatments, the viscosity reducing is linked to the polymeric material removal with high molecular weight. As the viscosity is strongly correlated with average degree of polymerization of the fibers, this reducing is related to the removal of polymers with high polymerization degree.

The lignin content in the removed material with peeling treatment showed a value almost three times higher than the fiber, showing that fines are lignin-rich.

Xylans content found in the fines fraction showed a value of $12 \%$. If we consider the lignin content found we can conclude that the cellulose fraction is the one more significant.

Fractionation and peeling treatments affected negatively the oxygen delignification leading to the reduction of the delignification efficiency. However, lignin Klason analysis showed that there was a higher lignin removal with treatments. A possible explanation for this difference may be the influence of other structures besides lignin, such as LCC's, HexA's and extractives on kappa number.

Peeling treatment doesn't effectively decrease fiber charge for all pulps, since the peeling reduces considerably fiber charge for samples with high content of ionizable groups. Therefore, decreased acids groups content of all studied pulps.

\section{References}

1. Samistraro G. Propriedades químicas e fisicas da polpa e papel Kraft por espectroscopia no infravermelho próximo (NIR). [Dissertação de Mestrado]. Curitiba: Universidade Federal do Paraná; 2008. 115 f.

2. Dang Z. The Investigation of Carboxyl Groups of Pulp Fibers during Kraft Pulping, Alkaline Peroxide Bleaching, and TEMPO-mediated Oxidation. [Doctoral Thesis]. Atlanta: School of Chemical and Biomolecular Engineering, Georgia Institute of Technology; 2007. $206 \mathrm{f}$.

3. Heijnesson A, Simonson R, Westermark U. Removal of Lignin-rich Surface Material from Unbleached Kraft Fibres. Holzforschung. 1995;49(4):313-318.

4. Sjöberg J, Kleen M, Dahlman O, Agnemo R, Sundval H. Analyses of carbohydrates and lignin in the surface and inner layers of softwood pulp fibers obtained employing various alkaline cooking processes. Nordic Pulp \& Paper Research Journal. 2002;17(3):295-301.

5. Timell TE. Wood Hemicelluloses. I. Advances in Carbohydrate Chemistry. 1964;19:247-302.

6. Berggren R. Cellulose degradation in pulp fibers studied as changes in molar mass distributions. [Doctoral Thesis]. Stockholm: Royal Institute of Technology, Department of Fibre and Polymer Technology; 2003. $81 \mathrm{f}$.
7. Pinto PC, Evtuguin DV, Pascoal Neto C. Structure of hardwood glucoronoxylans: modifications and impact on pulp retention during wood kraft pulping. Carbohydrate Polymers. 2005;60(4):489497.

8. Kallmes O. The Distribution of the Constituents Across the Wall of Unbleached Spruce Sulfite Fibers. [Doctoral Thesis] Appleton: Institute of Paper Chemistry; 1959. $77 \mathrm{f}$.

9. Dahlman O, Jacobs A, Sjöberg J. Molecular properties of hemicelluloses located in the surface and inner layers of hardwood and softwood pulps. Cellulose. 2003;10(4):325-334.

10. Sjoberg J. Characterization of chemical pulp fibers surfaces with an emphasis on the hemicelluloses. [Doctoral Thesis]. Stockholm: Royal Institute of Technology, Department of Fibre and Polymer Tecnology; 2002. $56 \mathrm{f}$.

11. Buchert J, Carlsson G, Viikari L, Ström G. Surface Characterization of Unbleached Kraft Pulps by Enzymatic Peeling and ESCA. Holzforschung. 1996;50(1):69-74.

12. Sundin J. Precipitation of Kraft Lignin under Alkaline Conditions. [Doctoral Thesis]. Stockholm: Royal Institute of Technology, Department of Pulp and Paper Chemistry and Technology; 2000 .

13. Fuhrmann A, Kleen M, Koljonen K, Österberg M, Stenius P. Precipitation of Lignin and Extractives from Bleaching Filtrates - Effects on Pulp Properties. In: Proceedings of TAPPI International Pulp Bleaching Conference; 2002 May 19-23; Portland, OR, USA.

14. Du X, Gellerstedt G, Li J. Universal fractionation of lignincarbohydrate complexes (LCCs) from lignocellulosic biomass: an example using spruce wood. The Plant Journal. 2013;74(2):328338. DOI: $10.1111 /$ tpj.12124

15. Li J, Sevastyanova O, Gellerstedt G. The distribution of oxidizable structures in ECF-and TCF-bleached kraft pulps. Nordic Pulp \& Paper Research Journal. 2002;17(4):415-419.

16. Costa MM, Colodette JL. The impact of kappa number composition on eucalyptus kraft pulp bleachability. Brazilian Journal of Chemical Engineering. 2007;24(1):61-71.

17. Hansson JA, Hartler N. Sorption of hemicelluloses on cellulose fibers. I. sorption of xylans. Svensk Papperstidning. 1969;72(17):521-530.

18. Dahlman O, Jacobs A, Sjöberg J. Xylan structure and distribution in kraft pulp fibers. In: $10^{\text {th }}$ International Symposium on Wood and Pulping Chemistry. 1999 Jun 7-10; Yokohama, Japan. V. 1. p. 186-189.

19. Buchert J, Teleman A, Harjubapaa V, Tenkanem M, Viikari L, Vuorinem T. Effect of cooking and bleaching on the structure of xylan in conventional pine kraft pulp. Tappi Journal. 1995;78(11):125-130.

20. Laine J, Buchert J, Viikari L, Stenius P. Characterization of Unbleached Kraft Pulps by Enzymatic Treatment, Potentiometric Titration and Polyeletrolyte Adsorption. Holzforschung. 1996;50(3):208-214.

21. Bhardwaj NK, Duong TD, Hoang V, Nguyen KL. Determination of fiber charge components of Lo-Solids unbleached kraft pulps. Journal of Colloid and Interface Science. 2004;274(2):543-549. 
22. Buchert J, Tenkanem M, Tamminem T. Characterization of carboxylic acids during kraft and superbatch pulping. Tappi Journal. 2001;84(4):70.
23. Kangas H, Pöhler T, Heikkurinen A, Kleen M. Development of the mechanical pulp fibre surface as a function of refining energy. Journal of Pulp and Paper Science. 2004;30(11):298-306. 